\title{
Blog-based Nutrition Education for College Students
}

\author{
Wan-Ju J. Yen
}

Department of Applied Health Sciences, Indiana State University, United States

Copyright $\bigcirc 2015$ by authors, all rights reserved. Authors agree that this article remains permanently open access under the terms of the Creative Commons Attribution License 4.0 International License

\begin{abstract}
College students consume less fruits and vegetables than MyPlate recommendations in the diet. Young adults need to develop healthy behaviors early to avoid chronic disease incidences. This study aimed to assess the impact of a blog-based nutrition education on six food groups (whole grain, fruit, vegetable, protein, dairy, oil) and omega-3 (n-3) fatty acids (FA) consumption in college students. A total of 86 students who registered in Spring 2012 at a southern university in the United States were participated. A 6-week education was studied, which one group received MyPlate information plus n-3 FA information, whereas the other group received MyPlate information only. There were significant differences on fruit, vegetable, and protein group consumption between the two groups, but no difference on n-3 FA consumption. There was significant difference in self-efficacy to include n-3 FA at meals among the two groups. This education might improve some food group consumption, but not on n-3 FA consumption in college students.
\end{abstract}

Keywords Blog, Nutrition Education, College Students

\section{Introduction}

Many Americans have had inadequate intake of fruits and vegetables. Thus, various dietary guidelines such MyPlate (USDA) has recommended an increased consumption of these food groups. In 2013, there were $38.5 \%$ adults reported consumed fruits less than one time daily, and $22.4 \%$ consumed vegetables less than one time daily [1]. MyPlate recommends filling half of the plate with fruits and vegetables at every meal, which includes five to nine servings of these two food groups daily. For some nutrients people consumed too much, such as saturated fat, trans fat, sugar and sodium, and these relate to chronic diseases. The new 2015-2020 Dietary Guidelines for Americans also emphasize to minimize sugar consumption. Poor nutrition could lead to chronic disease incidences, such as diabetes, heart diseases and cancers.

Omega-3 (n-3) fatty acids (FA) consumption has been found to benefit health and inadequate n-3 FA intake may lead to some chronic diseases. Omega-3 fatty acids are essential fatty acids. These include alpha-Linolenic acid (ALA), eicosapentaenoic acid (EPA) and docosahexaenoic acid (DHA). ALA usually comes from plant sources, such as flaxseed, walnut. Oily fish, such as salmon, mackerel, herring are good sources of EPA and DHA. Omega-3 fatty acids intake has many benefits, such as heart protection, eye function, brain development, cognitive decline prevention [2]. The American Heart Association (AHA) recommends eating fish (particularly fatty fish such as mackerel, lake trout, herring, sardines, albacore tuna, and salmon) at least two times a week. Symptoms of omega-3 fatty acid deficiency include fatigue, poor memory, dry skin, heart problems, mood swings or depression, and poor circulation [3].

Many studies have found the relation between weight and chronic disease incidences [4-6]. In 2014, nineteen states (Alabama, Arkansas, Delaware, Georgia, Indiana, Iowa, Kansas, Kentucky, Louisiana, Michigan, Missouri, North Dakota, Ohio, Oklahoma, Pennsylvania, South Carolina, Tennessee, Texas and Wisconsin) had obesity prevalence between $30 \%$ to $35 \%$, and three states (Arkansas, Mississippi and West Virginia) had a prevalence of obesity of $35 \%$ or greater [7]. Across regions in the US, the Midwest had the highest prevalence of adult obesity (30.7\%), followed by the South (30.6\%) [7]. Rates for hypertension and diabetes for the South were also the highest in the nation $[8,9]$. Nationwide, $16.6 \%$ of high school students (9 to 12 grade) were overweight and $13.7 \%$ were obese [10]. Transition between adolescence and adulthood, a common age for college attendance, frequently is accompanied by dramatic and inappropriate weight gain [11]. It is critical young adults need to develop healthy behaviors early to avoid the incidences.

Studies indicate many college students have poor nutrition and health status. For example, college students did not obtain the recommended "5 A Day" servings of fruits and vegetables [12]. Nelson et al. [13] found students at four-year colleges reported at least three servings less than national dietary recommendations on fruits and vegetables. While many studies have assessed students' diets in general, few have assessed student's n-3 FA intake. Omega-3 fatty acids, have multiple benefits for young adults, such as 
decreasing LDL oxidation [14], asthma incidences [15], depressive symptoms [16], and improves cognition [17]. McKenna et al. [18] found consumption of n-3 FA among college-age women $(0.8 \mathrm{~g} / \mathrm{d})$ fell below adequate intake (AI) of $1.1 \mathrm{~g} / \mathrm{d}$. It is important to provide nutrition education to college students on the benefits and how to incorporate n-3 FA in the diet.

There were studies demonstrated nutrition interventions for college students using traditional class lecture [19-21], online course [22], brochure and text messaging [21] significantly increased healthy food consumptions, but these studies were not specifically on n-3 FA. A tailored, web-based interactive nutrition program could potentially be used to provide individualized nutrition information to encourage college students to adopt healthy eating behaviors [23]. Blog experience was positive and enhanced undergraduate students' overall learning, in particular helping them think about concepts outside of the classroom [24]. In O'Donnell et al. [25] study, the 10-week web-based intervention was effective to increase the consumption of fruits and vegetables with a goal setting. A 5-week, web-based intervention to improve self-efficacy, outcome expectations, and self-regulation to increase intake of dairy products by college students showed a successful results in improving self-efficacy for total dairy intake and self-regulation, but did not improve outcome expectations or dairy intake [26]. These studies did not emphasize on n-3 FA.

The purpose of this study was to assess the effectiveness of a 6-week online blog, nutrition education on adopted MyPlate and n-3 FA information to improve dietary intake and self-efficacy for college students age over 18. The hypotheses for this study were: 1) participants' consumption of all six food groups would be significantly greater after using the blog with MyPlate information than before using the blog., 2) participants using blogs provided with additional n-3 FA information would have a greater increase of n-3 FA consumption than participants who were not provided with the additional n-3 FA information, 3) repeated exposure of information would increase the food group consumption.

\section{Materials and Methods}

\subsection{Participants}

Prior to data collection, the current study was approved by the Institutional Review Board (IRB) of the Western Kentucky University in the United States, which IRB ensures the study is conducted in accordance with all federal, institutional, and ethical guidelines. Once approval was granted, the author sent a mass e-mail to undergraduate and graduate students who had registered for classes at the University for the Spring 2012 semester. The mass e-mail included one link for the informed consent form and another link for the demographic questionnaire on Qualtrics, an online survey system (Qualtrics, Provo, UT, USA, 2012). The purpose of the first three questions in the demographic questionnaire was to screen out those students who did not meet the inclusion criteria for the current study. Students not meeting the inclusion criteria were those who were less than 18 years of age, nutrition major, or who had taken a Human Nutrition course at the University at which the current study was conducted. In 2012, undergraduates comprised $86 \%$ of the total student enrollment: freshman (27\%), sophomore $(18 \%)$, junior (18\%) and senior (25\%). About three of every five $(59 \%)$ students were female. There were a higher percentage of females among graduate students (approximately $70 \%$ ) than among undergraduate students (58\%) [27].

Among the 16,687 students who had been contacted to participate in the study, 602 students responded to the demographic questionnaire. Of these students, 558 students completed the demographic questionnaire and met the inclusion criteria. Two questionnaires (the food frequency questionnaire (FFQ) and a self-efficacy questionnaire) were sent to these 558 students. The researcher then randomly assigned each of the 558 participants into either Group A $(n=279)$ or into Group B $(n=279)$. However, only the responses of those participants who completed the nutrition education, the FFQ and self-efficacy questionnaires at three different time points were included in the data analysis. Thus, data from a total of 86 participants (Group $A=41$, Group $\mathrm{B}=45$ ) completed the nutrition education as well all assessments were analyzed in the current study.

\subsection{Procedures}

Group A received information focused on the MyPlate. Group B received the same information as Group A plus additional information about n-3 FA. The n-3 FA information included the introduction of n-3 FA, n-3 FA food sources ("What is in the group?"), described the recommended n-3 FA amounts for the college-age population ("How much is needed?"; "What counts as an ounce?"), and health benefits of n-3 FA for this age group ("Health implications"). Each blog entry was a module, which consisted of food groups information in the sections of "What is in the group?", "How much is needed (for the group)?", "What counts as an ounce/a cup?", and "Health implications". The module content was adapted from the MyPlate website [28]. Participants could ask the principal investigator (PI) questions directly via email during the study and post questions at the end of each blog module. Participants were able to access the blog using any electronic device at any time and read all modules at once through at the end of the study.

Participants received weekly e-mails with the module's web link for six consecutive weeks from early April to mid-May, 2012 (Figures 1, 2). Each module was a blog entry, and all modules were from the same blog site (Blogger) [29]. 
The first module was the introduction of MyPlate ("What is MyPlate?"), nutrition facts label [30], and portion size charts. The second module included information about grain, protein, and oil groups. Whole grains were the major concept in the grain group as college students consume inadequate whole grains in the diet [20]. The third module included information about fruit, vegetable, and dairy groups in MyPlate. The second and third modules identified food sources in each food group, recommended the appropriate number of ounces/cups for the college-age group (2000 calories for females, 3000 calories for males), explained what counts as an ounce/cup, and provided health implications of each food group. Super Tracker was introduced at the end of the second module to help participants track their daily food consumption. Super Tracker is the online tool in ChooseMyPlate website that allows individuals to plan, analyze, and track their diet and physical activity [28]. There were five review questions at the end of the third module for participants to assess the MyPlate information learned in modules one to three.

The purpose of the fourth to sixth modules was to reinforce information presented in modules one to three, respectively. The reinforcing modules were tips from MyPlate to include fruits, vegetables, and whole grains in the diet and make wise choices for protein and dairy products. At the end of each blog entry, the MyPlate website was provided as a reminder.

\subsection{Questionnaires}

Online assessment tools included a demographic questionnaire, a FFQ, and a self-efficacy questionnaire. The questionnaires were administered through Qualtrics. The FFQ was a modified version from a previous FFQ [31] and MyPlate food groups were also included. The FFQ assessed the frequency and usual serving size (small, medium, large) of food items consumed in the past month. The self-efficacy questionnaire was adapted from the Physical Activity and Healthy Food Efficacy Scale for Children (PAHFE) established by Perry et al. [32]. Each question had the answer choices of "completely uncertain", "somewhat uncertain", "somewhat certain", and "completely certain". Validity was tested using peer professionals and minor changes were made to help clarify the FFQ.

The demographic questionnaire was sent to all registered students the first week of April. The first FFQ and self-efficacy questionnaires were then sent to students who completed the demographic questionnaire and met the inclusion criteria $(\mathrm{n}=558)$. After one week, the participants were randomly divided into Group A or Group B. The second and third FFQs and self-efficacy questionnaires were sent to the participants at the third week (the end of April) and the sixth week (mid-May), respectively. Reminder emails were sent to non-corresponding participants from the online survey system one week after FFQ and self-efficacy questionnaire were distributed. Participants completing all three sets of questionnaires were eligible for incentive.

\subsection{Statistical Analyses}

Data were analyzed using SPSS (Version 22, Armonk, NY, USA, 2013). Descriptive statistics and Univariate Analysis of Variance were used to describe the background information of the participants and analyze the effects/interactions between interventions and times for all the assessments. Questionnaire data were only analyzed with completion of all three time points. The statistical significance level was set at $\mathrm{p}<.05$.

\section{Results}

\subsection{Background Information}

Table 1. Characteristics of the participants

\begin{tabular}{|c|c|c|c|}
\hline Characteristic & Male & $\begin{array}{c}\text { Group A } \\
(\mathrm{n}=41) \\
\text { No. }(\%)\end{array}$ & $\begin{array}{c}\text { Group Ba,b } \\
(\mathrm{n}=44) \\
\text { No. }(\%)\end{array}$ \\
\hline \multirow{2}{*}{ Gender } & Female & $33(80.5 \%)$ & $9(20.5 \%)$ \\
& Caucasian & $35(79.5 \%)$ \\
\hline & African & $36(87.8 \%)$ & $35(79.5 \%)$ \\
& American & $2(4.9 \%)$ & $2(4.5 \%)$ \\
Ethnicity & Hispanic & 0 & $1(2.3 \%)$ \\
& American & $3(7.3 \%)$ & $6(13.6 \%)$ \\
& Indian & & \\
& Freshman & $2(4.9 \%)$ & $8(18.2 \%)$ \\
Student & Sophomore & $7(17.1 \%)$ & $6(13.6 \%)$ \\
classification & Junior & $7(17.1 \%)$ & $13(29.5 \%)$ \\
& Senior & $14(34.1 \%)$ & $9(20.5 \%)$ \\
& Graduate & $11(26.8 \%)$ & $8(18.2 \%)$ \\
\hline & None & $2(4.9 \%)$ & $5(11.4 \%)$ \\
Eat out & $1-5$ & $38(92.7 \%)$ & $36(81.8 \%)$ \\
(time/week) & $6-10$ & $1(2.4 \%)$ & $2(4.5 \%)$ \\
& $10+$ & 0 & $1(2.3 \%)$ \\
\hline \multirow{2}{*}{ On diet } & No & $29(70.7 \%)$ & $31(70.5 \%)$ \\
& Yes & $12(29.3 \%)$ & $13(29.5 \%)$ \\
\hline
\end{tabular}

${ }^{a}$ Mixed-model analysis indicated no significant difference between Group A and Group B on any of the demographic variables. Results were considered significant at $\mathrm{p}<.05$. Group A participants received information focused on MyPlate. Group B received MyPlate information and additional information on n-3 fatty acids.

${ }^{\mathrm{b}}$ One less Group B participant number due to incomplete questionnaires data.

${ }^{\mathrm{c}}$ Student classification refers to the names for the four undergraduate years (freshman, sophomore, junior, senior) and graduate.

The summary of the characteristics of participants is presented in Table 1. Among all participants $(n=85)$, eight participants had taken nutrition courses in high school, and 12 participants had taken nutrition courses at other colleges or universities. Among the 85 participants, $68(80 \%)$ were female, and $62(73 \%)$ were of upper level classification (junior, senior and graduate levels). Body mass index (BMI) was calculated based on the self-reported height and weight information in the demographic questionnaire. There was no significant difference in BMI between Group A (25.2 \pm 6.5 $\left.\mathrm{kg} / \mathrm{m}^{2}\right)$ and Group B $\left(25.1 \pm 6.2 \mathrm{~kg} / \mathrm{m}^{2}\right)$. Eating out has been identified a factor that impacts overall eating behavior [33]. 


\subsection{Food Group Consumption}

The food group consumption between Group A and Group $B$ is presented in Table 2. Since there was no significant difference of food group consumption between Group A and Group $\mathrm{B}$ at baseline, $3^{\text {rd }}$, and $6^{\text {th }}$ weeks; no interaction between the intervention and the time lapse, data for baseline, $3^{\text {rd }}$, and $6^{\text {th }}$ weeks were combined to evaluate the overall difference between Group A and Group B. Group B consumed more servings in all food groups, except the dairy group, when compared with Group A. Both Group A and Group B had lower than MyPlate recommended servings in all six food groups. The results shows that when comparing Group A with Group B, there were significant differences on the vegetable group $\left(\mathrm{F}_{2,192}=3.359, \mathrm{p}=.037\right)$, the fruit group $\left(\mathrm{F}_{2,189}=3.463, \mathrm{p}=.033\right)$, and the protein group $\left(\mathrm{F}_{2,187}=3.374\right.$, $\mathrm{p}=.036$ ). Fruit and vegetable group consumption were one-fifth of the recommended servings in both Group A and Group B. Group A's consumption was less than one serving in fruit and vegetable groups $(.87$ and .97 serving, respectively).

Table 2. The comparison of food group consumption between Group A and Group B

\begin{tabular}{|c|c|c|}
\hline $\begin{array}{c}\text { Food group } \\
(\text { Daily recommendation })^{\mathrm{a}}\end{array}$ & $\begin{array}{c}\text { Group A } \\
(\text { MyPlate }) \\
(\mathrm{n}=40)\end{array}$ & $\begin{array}{c}\text { Group B } \\
(\text { MyPlate }+ \\
\mathrm{n}-3) \\
(\mathrm{n}=41)\end{array}$ \\
\hline $\begin{array}{c}\text { Whole Grain } \\
(3-5 \text { oz. equivalent; } 3-5 \text { servings })\end{array}$ & $1.0 \pm 1.25$ & $1.17 \pm 1.39$ \\
\hline $\begin{array}{c}\text { Vegetable } \\
(2.5-4 \text { cups; } 5-8 \text { servings })\end{array}$ & $.97 \pm .94$ & $1.34 \pm 1.41^{*}$ \\
\hline $\begin{array}{c}\text { Fruit } \\
(2-2.5 \text { cups; } 4-5 \text { servings })\end{array}$ & $.87 \pm .93$ & $1.04 \pm 1.07^{*}$ \\
\hline $\begin{array}{c}\text { Dairy } \\
(3 \text { cups; } 3 \text { servings })\end{array}$ & $1.08 \pm 1.05$ & $.98 \pm .91$ \\
\hline $\begin{array}{c}\text { Protein } \\
(5.5-7 \text { oz. equivalent; } 1.83-2.33 \\
\text { servings })\end{array}$ & $1.04 \pm .78$ & $1.27 \pm 1.26^{*}$ \\
\hline $\begin{array}{c}\text { Oil } \\
(6-10 \text { tsp; 6-10 servings })\end{array}$ & $.66 \pm .76$ & $.67 \pm .60$ \\
\hline
\end{tabular}

Values represent mean \pm standard deviation. All values are servings per day. ${ }^{a}$ The food group recommendation is based on MyPlate recommendation for 2000 and 3000 calories. ${ }^{*} \mathrm{p}<.05$

\subsection{Omega-3 Fatty Acid Consumption}

There was no difference between Group A and Group B for the mean consumption of n-3 FA from food groups, Groups A and B were combined for analysis. When looking at n-3 FA content in each food group, there was no significant difference among three time periods (Table 3). For n-3 FA from the whole grain and dairy groups, consumption decreased at $3^{\text {rd }}$ week $(.87$ and $.47 \mathrm{~g} / \mathrm{mo}$, respectively) but increased at $6^{\text {th }}$ week $(1.18$ and $.50 \mathrm{~g} / \mathrm{mo})$. For fruit and protein groups, consumption increased first at $3^{\text {rd }}$ week ( 1.11 and $32.98 \mathrm{~g} / \mathrm{mo}$, respectively) but decreased at $6^{\text {th }}$ week $(.86$ and $21.76 \mathrm{~g} / \mathrm{mo})$. For the vegetable group, $\mathrm{n}-3$ FA consumption decreased at both $3^{\text {rd }}(1.56 \mathrm{~g} / \mathrm{mo})$ and $6^{\text {th }}$ week $(1.52 \mathrm{~g} / \mathrm{mo})$, yet the oil group consumption increased at both $3^{\text {rd }}(2.82 \mathrm{~g} / \mathrm{mo})$ and $6^{\text {th }}$ week $(3.54 \mathrm{~g} / \mathrm{mo})$. Overall total consumption of n-3 FA increased at $3^{\text {rd }}$ week $(39.82 \mathrm{~g} / \mathrm{mo})$ but then decreased at $6^{\text {th }}$ week $(29.37 \mathrm{~g} / \mathrm{mo})$. The total $\mathrm{n}-3$ FA consumption was lower than recommendation at baseline and $6^{\text {th }}$ week $(.98 \mathrm{~g} / \mathrm{d})$.

Table 3. Mean consumption of n-3 fatty acids from food groups at baseline, third week and sixth week of the study

\begin{tabular}{|c|c|c|c|}
\hline \multirow{2}{*}{$\begin{array}{c}\text { Food group } \\
(\mathrm{g} / \mathrm{mo})\end{array}$} & Baseline & $3^{\text {rd }}$ week & $6^{\text {th }}$ week \\
\cline { 2 - 4 } & \multicolumn{3}{|c|}{} \\
\hline Whole Grain & $1.50 \pm 2.78$ & $.87 \pm 1.38$ & $1.18 \pm 2.03$ \\
\hline Vegetable & $1.90 \pm 3.62$ & $1.56 \pm 2.64$ & $1.52 \pm 2.61$ \\
\hline Fruit & $1.07 \pm 1.23$ & $1.11 \pm 3.17$ & $.86 \pm 1.15$ \\
\hline Dairy & $.59 \pm .75$ & $.47 \pm .64$ & $.50 \pm .66$ \\
\hline Protein & $22.56 \pm 52.39$ & $32.98 \pm 111.09$ & $21.76 \pm 56.15$ \\
\hline Oil & $1.72 \pm 5.91$ & $2.82 \pm 10.40$ & $3.54 \pm 13.14$ \\
Total & $29.35 \pm 58.11$ & $39.82 \pm 119.74$ & $29.37 \pm 67.59$ \\
\hline
\end{tabular}

Values represent mean \pm standard deviation. The values are based on 86 participants.

\subsection{Self-efficacy}

The summary of self-efficacy to include whole grains and n-3 FA in various settings between Group A and Group B is presented in Tables 4 to 6 . There was significant difference between Group A and Group B to include n-3 FA at meals $(p=.026)$. The lowest self-efficacy in both groups was when "purchasing foods" of whole grains and n-3 FA foods. In both Group A and Group B, participants had lower self-efficacy to include whole grains than n-3 FA in all settings (at meals, cooking, eating out, and purchasing foods) (Table 4). Group A decreased the self-efficacy to include n-3 FA at meals, cooking, eating out and purchasing foods when compare the baseline and at the $6^{\text {th }}$ week. Group B increased the self-efficacy to include n-3 FA at meals and purchasing foods at $3^{\text {rd }}$ week, but decreased at $6^{\text {th }}$ week (Table 5). For the self-efficacy to include whole grains, it was similar to include n-3 FA at meals, cooking, eating out and purchasing foods; except Group A decreased at $3^{\text {rd }}$ week, and increased at $6^{\text {th }}$ week at purchasing foods. Group B at meals and eating out decreased at $3^{\text {rd }}$ week and then increased at $6^{\text {th }}$ week; purchasing foods increased at $3^{\text {rd }}$ week and then decreased at $6^{\text {th }}$ week (Table 6). Overall, Group B had lower self-efficacy to include whole grains and n-3 FA in various settings than Group A. 
Module 2 (Apr. 15-21)

Grain group; Protein group; Oil group; Super Grain group; Protein group; Oil group; N-3 fattly Tracker

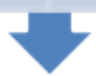
acids; Super Tracker

Module 3 (Apr. 22-28)

Fruit group; Vegetable group; Dairy group; $\quad$ Fruit group; Vegetable group; Dairy group; N-3 Review Questions fatty acids; Review Questions

\section{Module 4 (Apr. 29- May 5)}

Tips to read Nutrition Facts Label, Portion Size Tips to read Nutrition Facts Label, Portion Size

\section{Module 5 (May 6-12)}

Tips to include whole grains in the diet and make lips to include whole grains, n-3 fatty acids in wise choices for protein products the diet, make wise choices for protein products

\section{Module 6 (May 13-19)}

Tips to include fruits and vegetables in the diet, lips to include fruits, vegetables, n-3 fatty acids make wise choices for dairy products

Figure 1. Flow chart of study procedure 
$1^{\text {st }}$ week in April (Apr. 1-7)

- Sent demographic questionnaire to all 16687 students. 602 responded. 558 completed and met the inclusion criteria.

- Sent $1^{\text {st }}$ FFQ and self-efficacy questionnaire to 558 .

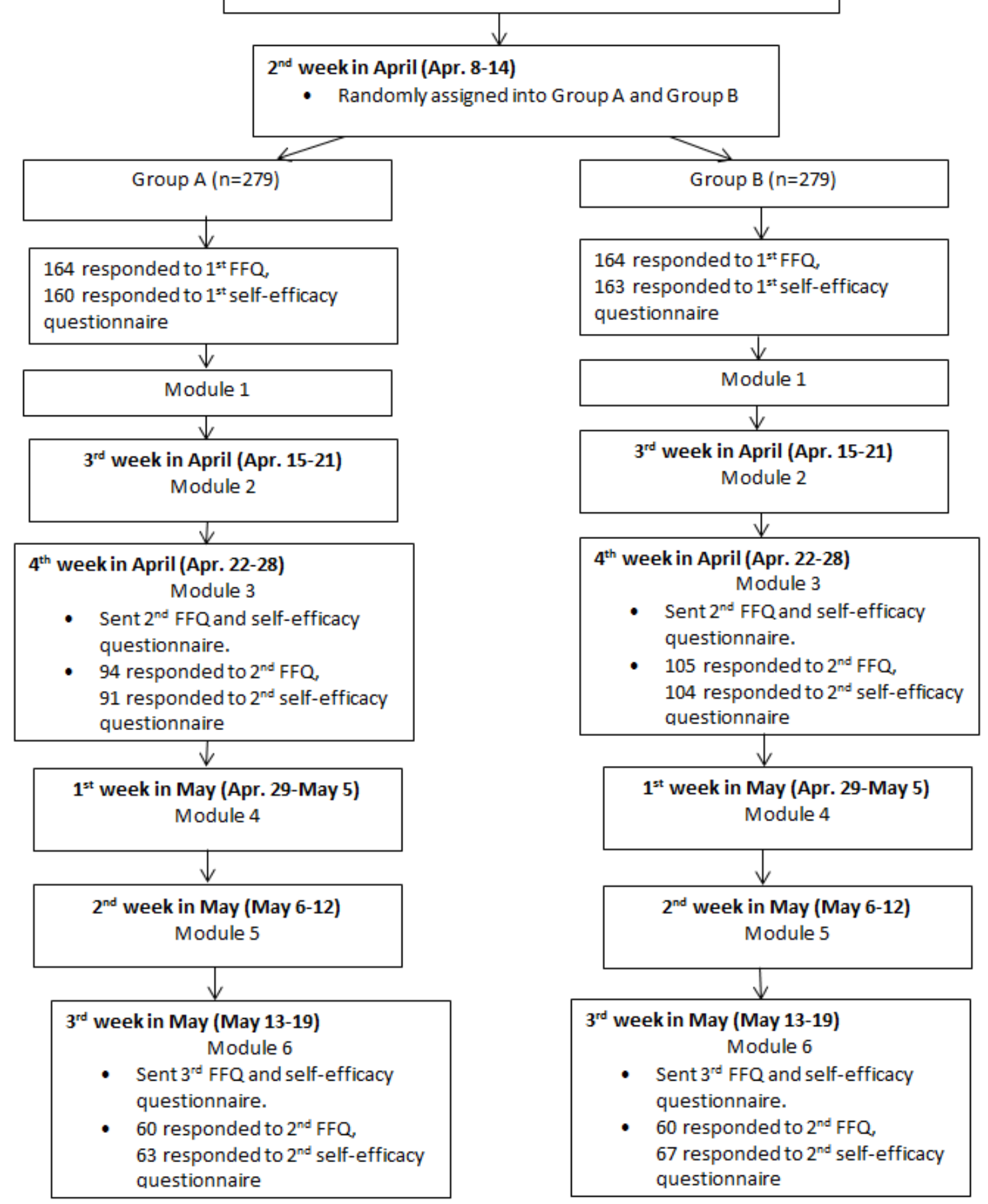

Figure 2. Time line of the study procedure 
Table 4. The comparison of self-efficacy to include whole grains and n-3 fatty acids in various settings between Group A and Group B

\begin{tabular}{|c|c|c|c|c|}
\hline \multirow[t]{2}{*}{ Setting } & \multicolumn{2}{|c|}{$\begin{array}{c}\text { Group A } \\
\text { (MyPlate) } \\
(\mathrm{n}=41)\end{array}$} & \multicolumn{2}{|c|}{$\begin{array}{c}\text { Group B } \\
(\text { MyPlate }+n-3) \\
(n=45)\end{array}$} \\
\hline & Whole grain & $n-3$ & Whole grain & $n-3$ \\
\hline At meals & $1.93 \pm .85$ & $2.58 \pm 1.03$ & $1.90 \pm .93$ & $2.38 \pm 1.04^{*}$ \\
\hline Cooking & $1.98 \pm .95$ & $2.63 \pm 1.08$ & $1.87 \pm 1.05$ & $2.38 \pm 1.15$ \\
\hline Eating out & $2.61 \pm .93$ & $3.06 \pm .91$ & $2.58 \pm .1 .03$ & $2.87 \pm 1.01$ \\
\hline Purchasing foods & $1.84 \pm .94$ & $2.53 \pm 1.04$ & $1.79 \pm .93$ & $2.29 \pm 1.17$ \\
\hline
\end{tabular}

Data are means \pm standard deviation. The greater the score, the greater the confidence in one's ability to include whole grains and $n-3$ fatty acids in the setting (1, completely uncertain; 2 , somewhat uncertain; 3 , somewhat certain; 4 , completely certain)

*Statistically significant difference to include n-3 FA at meals between Group A and Group B. $p<.05$.

Table 5. Self-efficacy to include n-3 fatty acids in various settings at baseline, third week and sixth week among Group A and Group B in the study

\begin{tabular}{|c|c|c|c|c|c|c|}
\hline \multirow{2}{*}{ Setting } & \multicolumn{3}{|c|}{$\begin{array}{c}\text { Group A } \\
\text { (MyPlate) } \\
(\mathrm{n}=41)\end{array}$} & \multicolumn{3}{|c|}{$\begin{array}{c}\text { Group B } \\
\text { (MyPlate+n-3) } \\
(\mathrm{n}=45)\end{array}$} \\
\cline { 2 - 8 } & Baseline & $3^{\text {rd }}$ week & $6^{\text {th }}$ week & Baseline & $3^{\text {rd }}$ week & $6^{\text {th }}$ week \\
\hline At meals & $2.68 \pm 1.06$ & $2.63 \pm 1.11$ & $2.41 \pm .92$ & $2.42 \pm 1.12$ & $2.44 \pm 1.08$ & $2.27 \pm .94$ \\
\hline Cooking & $2.76 \pm 1.04$ & $2.63 \pm 1.11$ & $2.51 \pm 1.10$ & $2.53 \pm 1.22$ & $2.47 \pm 1.20$ & $2.13 \pm .99$ \\
\hline Eating out & $3.27 \pm .87$ & $3.05 \pm .95$ & $2.85 \pm .88$ & $2.98 \pm 1.01$ & $2.96 \pm 1.07$ & $2.67 \pm .95$ \\
\hline Purchasing foods & $2.61 \pm 1.09$ & $2.59 \pm 1.11$ & $2.39 \pm .92$ & $2.24 \pm 1.26$ & $2.44 \pm 1.24$ & $2.18 \pm .98$ \\
\hline
\end{tabular}

Data are mean \pm standard deviation. The greater the score, the greater the confidence in one's ability to include n- 3 fatty acids in the setting ( $1=$ completely uncertain, $2=$ somewhat uncertain, $3=$ somewhat certain, $4=$ completely certain).

Table 6. Self-efficacy to include whole grains in various settings at baseline, third week and sixth week among Group A and Group B in the study

\begin{tabular}{|c|c|c|c|c|c|c|}
\hline \multirow{2}{*}{ Setting } & \multicolumn{3}{|c|}{$\begin{array}{c}\text { Group A } \\
\text { (MyPlate) } \\
(\mathrm{n}=41)\end{array}$} & \multicolumn{3}{|c|}{$\begin{array}{c}\text { Group B } \\
\text { (MyPlate }+\mathrm{n}-3) \\
(\mathrm{n}=45)\end{array}$} \\
\cline { 2 - 8 } & Baseline & $3^{\text {rd }}$ week & $6^{\text {th }}$ week & Baseline & $3^{\text {rd }}$ week & $6^{\text {th }}$ week \\
\hline At meals & $1.95 \pm .92$ & $1.95 \pm .87$ & $1.88 \pm .78$ & $2.00 \pm 1.09$ & $1.80 \pm .92$ & $1.89 \pm .78$ \\
\hline Cooking & $2.17 \pm 1.05$ & $1.98 \pm .99$ & $1.78 \pm .79$ & $1.98 \pm 1.22$ & $1.91 \pm 1.15$ & $1.71 \pm .73$ \\
\hline Eating out & $2.76 \pm .86$ & $2.63 \pm 1.02$ & $2.44 \pm .90$ & $2.69 \pm 1.08$ & $2.40 \pm 1.03$ & $2.64 \pm .96$ \\
\hline Purchasing foods & $1.83 \pm .97$ & $1.80 \pm 1.01$ & $1.88 \pm .87$ & $1.76 \pm 1.00$ & $1.84 \pm .98$ & $1.76 \pm .80$ \\
\hline
\end{tabular}

Data are mean \pm standard deviation. The greater the score, the greater the confidence in one's ability to include whole grains in the setting $(1=$ completely uncertain, $2=$ somewhat uncertain, $3=$ somewhat certain, $4=$ completely certain).

\section{Discussion}

The purpose of this study was to see if blog format could increase MyPlate food group consumption, and the additional n-3 FA information could increase n-3 FA consumption among participants. A study found technology-based activities can shape and characterize on autonomous awareness learning in college students [34]. For example, an e-mail-delivered intervention with goal setting improved nutrition and physical activity behaviors in African American college students [35]. Blogs seems to be a potential approach to improve health behaviors. Weblogs not only provide a learning environment and enhance creativity for college students, but also allow interaction and divergent thinking experiences [36]. In the current study, the blog provided nutrition information, but did not emphasize the goals (the food group servings and n-3 FA recommendations) substantially. This might lead to decrease self-efficacy due to no concrete goals. In the future, a study evaluation should send to participants at the end of the study to assess the feasibility and acceptability of the education.

The results of the present study showed the education may improve participants' fruit, vegetable, protein groups consumption. Inadequate fruit and vegetable consumption is always a concern for the public, including the college student population [12]. In the present study, the recommended food group servings were provided in the modules, and participants had the target fruit and vegetable amounts. Super Tracker was introduced to help participants to find out the exact recommended servings for each food group, which were based on user's age, gender and physical activity level. Super Tracker could also keep track of food group consumption. Even the food group recommendation information and the tool were introduced; fruit and vegetable 
consumption were still under MyPlate recommendations. There are many reasons people may or may not change behavior. Future studies need to specifically focus on fruit and vegetable groups. Also, all six food group consumption was under MyPlate recommendations. Future research could include interviews to explore possible reasons for not consuming adequate food groups. Even the study may improve protein group consumption, one argument is the sources of meat and beans and if majority of the foods are from "healthy foods", such as plant protein sources (beans, peas, nuts). Food preparation method is another concern, for example, if it is fried or baked. In the future research, the food preparation method could be assessed.

In the current study, the overall n-3 FA consumption increased at $3^{\text {rd }}$ week and decreased at $6^{\text {th }}$ week. At $6^{\text {th }}$ week, n-3 FA consumption was lower than the recommended amount, one gram per day [37]. The end of the current study was the final exam period. Healthy eating behavior was not students' priority at the busiest time of the semester. It was difficult for participants to incorporate new food items at this time. The education may have positive effects on n-3 FA consumptions in some food groups, such as whole grain, dairy, oil groups; but negative effects in fruit, vegetable, protein groups. It might be certain food groups remind participants of n-3 FA than the others and these food groups are easier to obtain, for example, nuts and seeds. Omega-3 FA consumption was not significantly different between Group A and Group B. In the future, nutrition education needs to emphasize n-3 FA information, specifically in each food group.

Self-efficacy is beneficial in initiation and maintenance of behavioral change [38]. In this study, purchasing whole grains and n-3 FA foods were at lowest self-efficacy when compared with other settings. There are too many food choices in the store and consumers usually have a difficult time to choose healthy foods. It might be participants either don't read or don't know how to interpret the food label and the ingredient list. Future studies could provide more food label examples and let participants to interpret the labels. Among whole grains and n-3 FA, participants had lower self-efficacy to include whole grains than n-3 FA in all settings. Whole grains may have not been directly specified on food packages and labels than n-3 FA. Participants were confident to include n-3 FA at meals, but didn't consume adequate amount of n-3 FA in the diet. It might be participants were not aware n-3 FA food sources. In future studies, food sources should include in the eating out topic and also to integrate grocery shopping tours to introduce whole grains and n-3 FA food sources. Participants decreased self-efficacy at the end of the study, which was not expected. It might be the nutrition information and examples in the modules did not correspond to what they found in local stores. The modules should include explicit information to the geographic needs.

Another objective of this study was to see if repetition was necessary by comparing the three time points. Long-term, repeated nutrition education is usually necessary to achieve lasting improvement in eating behavior, though it may have a greater measurable impact on short and medium- than on long-term outcomes [39]. Neither food group nor n-3 FA consumption had significant difference among three time points. When looking at n-3 FA consumption and self-efficacy, some values (total consumption, at meals self-efficacy, purchasing foods self-efficacy) increased at $3^{\text {rd }}$ week, but then decreased at $6^{\text {th }}$ week. This could be improved by adding more MyPlate supplemental information (such as cookbooks, recipes and menus) and techniques to enhance and reinforce self-efficacy.

There are several limitations in this study. This study included participants who were on a diet. This may have impacted the dietary consumption of participants. It is also possible that after signing up for the study, participants started to be aware of their diet. As participants joined the study voluntarily, these students might be more aware of nutrition and health than non-participants. Participant response rate dropped from the initial recruitment to the last questionnaire assessment. The declining response rate caused a problem with data analysis. One limitation is the use of a pre-post design without a "true" control group, which limits the ability to separate the effects of other nutrition information format. Follow up work would be necessary to figure out the information given in this study can truly cause behavior change as there are plethora of reasons why individuals choose and make decisions.

\section{Conclusions}

Healthy eating behavior is one important factor to prevent chronic diseases. Nutrition education can improve dietary practices and establish healthy eating behavior. This blog-based nutrition education based on MyPlate may improve fruit, vegetable, and protein group consumption, but not n-3 FA in college students. Practitioners could adopt and modify the blog format to design nutrition education for college student. Online Tools from the MyPlate website [28] could incorporate into the education session. As peer health educators have positive effects on promoting healthy behavior [40], MyPlate Campus Ambassadors [28] could also integrate into the education session.

\section{Acknowledgments}

This study received funding from Western Kentucky University new faculty grant and Indiana State University Center for Community Engagement.

The author thanks Dr. Shiaw-Fen Ferng for assistance with data analyses. 


\section{REFERENCES}

[1] CDC. (2015). Nutrition, physical activity and obesity data, trends and maps web site. Online available from http://www.cdc.gov/nccdphp/DNPAO/index.html

[2] G. Cole, Q. Ma, S. Frautschy. Omega-3 fatty acids and dementia. Prostaglandins Leukotrienes and Essential Fatty Acids, Vol. 81, No. 2-3, 213-221, 2009.

[3] University of Maryland Medical Center. (2015). Omega-3 fatty acids. Online available from http://umm.edu/health/medical/altmed/supplement/omega3-f atty-acids

[4] D. Canoy, B. J. Cairns, A. Balkwill, F. L. Wright, J. Green, G. Reeves, V. Beral. Body mass index and incident coronary heart disease in women: a population-based prospective study. BMC Medicine, Vol. 11, No. 1, 1-9, 2013.

[5] C. Kaneto, S. Toyokawa, Y. Miyoshi, Y. Suyama, Y. Kobayashi. Long-term weight change in adulthood and incident diabetes mellitus: MY Health up Study. Diabetes Research and Clinical Practice, Vol. 102, 138-146, 2013.

[6] D. Pisani, E. M. Paris, G. C. Dingli. Relation between obesity and the oestrogen receptor status of breast cancer. Malta Medical Journal, Vol. 26, No. 2, 10-14, 2014.

[7] CDC. (2015). Overweight and Obesity. Adult Obesity Facts. Obesity prevalence in 2014. Online available from http://www.cdc.gov/obesity/data/adult.html.

[8] L. E. Barker, K. A. Kirtland, E. W. Gregg, L. S. Geiss, T. J. Thompson. Geographic distribution of diagnosed diabetes in the U.S.: a diabetes belt. American Journal of Preventive Medicine, Vol. 40, No. 4, 434-439, 2011.

[9] C. Olives, R. Myerson, A. H. Mokdad, C. J. L. Murray, S. S. Lim. Prevalence, awareness, treatment, and control of hypertension in United States counties, 2001-2009. Plos One, Vol. 8, No. 4, e60308-e60308, 2013.

[10] L. Kann, S. Kinchen, S. L. Shanklin, K. H. Flint, J. Hawkins, W. A. Harris, R. Lowry, E. O'Malley Olsen, T. McManus, D. Chyen, L. Whittle, E. Taylor, Z. Demissie, N. Brener, J. Thornton, J. Moore, S. Zaza. Youth risk behavior surveillance--United States, 2013. Morbidity and Mortality Weekly Report. Surveillance Summaries, Vol. 63, No. Suppl 4, 1-168, 2014.

[11] S. B. Racette, S. S. Deusinger, M. J. Strube, G. R. Highstein, R. $H$. Deusinger. Weight changes, exercise, and dietary patterns during freshman and sophomore years of college. Journal of American College Health, Vol. 53, No. 6, 245-251, 2005.

[12] L. H. Wang, H. L. Yang, Y. C. Chen, R. Davis, M. E. Schwartz, C. F. Tam. A health probe in college students living in Los Angeles and in Taiwan: Dietary pattern, physical activity and energy balance. College Student Journal, Vol. 42, No. 3, 756-770, 2008.

[13] M. C. Nelson, N. I. Larson, D. Barr-Anderson, D. Neumark-Sztainer, M. Story. Disparities in dietary intake, meal patterning, and home food environments among young adult nonstudents and 2- and 4-year college students. American Journal of Public Health, Vol. 99, No. 7, 1216-1219, 2009.
[14] S. Egert, V. Somoza, F. Kannenberg, M. Fobker, K. Krome, H. F. Erbersdobler, U. Wahrburg. Influence of three rapeseed oil-rich diets, fortified with alpha-linolenic acid, eicosapentaenoic acid or docosahexaenoic acid on the composition and oxidizability of low-density lipoproteins: results of a controlled study in healthy volunteers. European Journal of Clinical Nutrition, Vol. 61, No. 3, 314-325, 2007.

[15] J. Li, P. Xun, D. Zamora, A. Sood, K. Liu, M. Daviglus, C. Iribarren, D. Jr. Jacobs, J. M. Shikany, K. He. Intakes of long-chain omega-3 (n-3) PUFAs and fish in relation to incidence of asthma among American young adults: The CARDIA study. American Journal of Clinical Nutrition, Vol. 97, No. 1, 173-178, 2013.

[16] A. T. Ginty, S. M. Conklin. Short-term supplementation of acute long-chain omega-3 polyunsaturated fatty acids may alter depression status and decrease symptomology among young adults with depression: A preliminary randomized and placebo controlled trial. Psychiatry Research, Vol. 229, 485-489, 2015.

[17] I. Bauer, M. Hughes, R. Rowsell, R. Cockerell, A. Pipingas, S. Crewther, D. Crewther. Omega-3 supplementation improves cognition and modifies brain activation in young adults. Human Psychopharmacology: Clinical \& Experimental, Vol. 29, No. 2, 133-144, 2014.

[18] D. A. McKenna, N. H. Herbold, D. M. Wolongevicz, K. M. Hendricks, J. M. Lacey. Intake of omega-3 polyunsaturated fatty acids among college-age women. Topics in Clinical Nutrition, Vol. 19, No. 2,107-116, 2004.

[19] E. Ha, N. Caine-Bish. Effect of nutrition intervention using a general nutrition course for promoting fruit and vegetable consumption among college students. Journal of Nutrition Education and Behavior, Vol. 41, No. 2, 103-109, 2009.

[20] E. Ha, N. Caine-Bish. Interactive introductory nutrition course focusing on disease prevention increased whole-grain consumption by college students. Journal of Nutrition Education and Behavior, Vol. 43, No. 4, 263-267, 2011.

[21] M. Shahril, W. Wan Dali, P. Lua. A 10-week multimodal nutrition education intervention improves dietary intake among university students: Cluster randomised controlled trial. Journal of Nutrition and Metabolism,1-11, 2013.

[22] K. H. Poddar, K. W. Hosig, E. S. Anderson-Bill, S. M. Nickols-Richardson, S. E. Duncan. Dairy intake and related self-regulation improved in college students using online nutrition education. Journal of the Academy of Nutrition and Dietetics,Vol. 112, No. 12, 1976-1986, 2012.

[23] T. M. Cousineau, D. L. Franko, M. Ciccazzo, M. Goldstein, E. Rosenthal. Web-based nutrition education for college students: Is it feasible? Evaluation and Program Planning, Vol. 29, No. 1, 23-33, 2006.

[24] O. Halic, D. Lee, T. Paulus, M. Spence. To blog or not to blog: Student perceptions of blog effectiveness for learning in a college-level course. The Internet and Higher Education, Vol. 13, 206-213, 2010.

[25] S. O'Donnell, G. W. Greene, B. Blissmer. The effect of goal setting on fruit and vegetable consumption and physical activity level in a web-based intervention. Journal of Nutrition Education and Behavior, Vol. 46, No. 6, 570-575, 2014. 
[26] K. H. Poddar, K. W. Hosig, E. S. Anderson, S. M. Nickols-Richardson, S. E. Duncan. Web-based nutrition education intervention improves self-efficacy and self-regulation related to increase dairy intake in college students. Journal of the American Dietetic Association, Vol. 110, No. 11, 1723-1727, 2010.

[27] T. Helbig, M. Bogard, L. Davis, S. Estes, M Foraker, S Hamlet, G Huff, J Hume, C Vincent. University Fact Book. Western Kentucky University, 2013.

[28] USDA. (2012). MyPlate 2012. Online available from http://www.choosemyplate.gov/

[29] http://webcollegenutrition.blogspot.com/?zx=e0a15ec374145 $65 \mathrm{a}$

[30] FDA. (2004). How to Understand and Use the Nutrition Facts Label. Online available from http://www.fda.gov/Food/Ingre dientsPackagingLabeling/LabelingNutrition/ucm274593.htm

[31] P. K. Ritter-Gooder, N. M. Lewis, K. B. Heidal, K. M. Eskridge. Validity and reliability of a quantitative food frequency questionnaire measuring n-3 fatty acid intakes in cardiac patients in the Midwest: A validation pilot study. Journal of the American Dietetic Association, Vol. 106, No. 8, 1251-1255, 2006.

[32] C. M. Perry, R. J. De Ayala, R. Lebow, E. Hayden. A validation and reliability study of the physical activity and healthy food efficacy scale for children (PAHFE). Health Education and Behavior, Vol. 35, No. 3, 346-360, 2008.

[33] P. Hu, W. Huang, R. Bai, F. Zhang, M. Sharma, Z. Shi, X. Xiao, A.S. Abdullah, Y. Zhao. Knowledge, attitude, and behaviors related to eating out among university students in China. International Journal of Environmental Research and
Public Health, Vol. 13, No. 7, 696, 2016.

[34] D. D. Ballén. The role of blogs and web resources in students' autonomous learning awareness. HOW: A Colombian Journal For Teachers of English, Vol. 21, No. 2, 10-30, 2014.

[35] E. Mackey, A. Schweitzer, M. E. Hurtado, J. Hathway, L. DiPietro, K. Y. Lei, C. J. Klein. The feasibility of an e-mail-delivered intervention to improve nutrition and physical activity behaviors in African American college students. Journal of American College Health, Vol. 63, No. 2, $109-117,2015$

[36] S. Auttawutikul, K. Wiwitkunkasem, D. R. Smith. Use of weblogs to enhance group learning and design creativity amongst students at a Thai University. Innovations in Education and Teaching International, Vol. 51, No. 4, 378-388, 2014

[37] C. G. Candela, L. B. López, V. L. Kohen. Importance of a balanced omega 6/omega 3 ratio for the maintenance of health. Nutritional recommendations. Nutricion Hospitalaria, Vol. 26, No. 2, 323-329, 2011.

[38] K. Glanz, B. K. Rimer, K. Viswanath. Health Behavior and Health Education. San Francisco, CA: Jossey-Bass Publishers, 2008.

[39] C. M. Devine, M. Jastran, C. Bisogni. It just really clicked: Participant-perceived outcomes of community nutrition education programs. Journal of Nutrition Education and Behavior, Vol. 38, No. 1, 42-49, 2006.

[40] S. White, Y. S. Park, T. Israel, E. D. Cordero. Longitudinal evaluation of peer health education on a college campus: Impact on health behaviors. Journal of American College Health, Vol. 57, No.5, 497-506, 2009. 